\title{
Audit of ultrasound measurement of invasive breast cancers compared with histological size
}

This article was published in the following Dove Press journal:

Clinical Audit

4 June 2010

Number of times this article has been viewed

\author{
Brian Mucci \\ Robert Shaw \\ Radiology Department, Southern \\ General Hospital, Glasgow, \\ Scotland, UK
}

Correspondence: Brian Mucci Radiology Department, Southern General Hospital, Govan Road, Glasgow, G5I 4TF, Scotland, UK

Tel +44 I4I 20I I 3 I0

Fax +44 4I 20III6I

Email brian.mucci@ggc.scot.nhs.uk

\begin{abstract}
An accurate measure of breast cancer size is important since it influences therapy choice and can be used to monitor response to treatment. Ultrasound is known to underestimate tumor size, but experienced operators should achieve a good correlation between measurements and histological size. There is a wide range of published correlation coefficients with a mean of 0.74 and range of 0.45 to 0.92 . Tumor type can influence the correlation with lobular carcinomas, in particular, being more difficult to visualize and measure on imaging. A minimum correlation of 0.6 with a desirable target of 0.75 seems achievable. This short report demonstrates how readily available software can be used to calculate and graphically display a correlation coefficient of ultrasound and histological tumor measurements. Using our results for one year, we illustrate the use of this software as an auditing tool.
\end{abstract}

Keywords: breast, ultrasound, audit, cancer

\section{Introduction}

Measurement of breast cancer size by ultrasound is important. Size can influence therapy plans for the patient and is also important for measuring response to adjuvant therapy. Ultrasound assessment is known to underestimate tumor dimensions compared to histology, ${ }^{1}$ but experienced operators should aim to achieve a good correlation between ultrasound measurement and histological size. Correlation refers to the departure of two random variables from independence. Ultrasound does not give exact histological size and tends to underestimate tumor dimensions. However, the relationship should be linear and ultrasound is widely used to approximate tumor size and monitor therapy in the clinical situation. ${ }^{1}$ For this reason, a parametric measure of correlation (Pearson's coefficient) has been applied in a number of publications. Its use was reviewed and tabulated by Pritt et al in 2004. ${ }^{2}$ Spearman's coefficient can be applied, but its use is best when the relationship between the factors is not linear. Previous publications have assumed a linear relationship and chosen Pearson's coefficient. Many software packages will allow simultaneous calculation of both figures. Radiologists measuring cancers aim for a correlation with histological size as close to 1.0 as possible. The correlation coefficient alone is not enough since viewing the distribution of data plots allows us to visually asses the linearity of the relationship and identify outliers. Correlation can be calculated and plotted easily using widely available software.

\section{Methods}

A standard correlation coefficient for which to aim must first be set. The goal is for a good linear correlation between tumor size by ultrasound and microscopic size. 
The literature shows a wide range of published Pearson's correlation coefficients. These were tabulated by Pritt et $\mathrm{al}^{2}$ who compared their results of 0.79 with 11 prior studies finding an overall mean of 0.74 and range of 0.45 to 0.92 . Tumor types can influence the correlation, with lobular carcinomas being more difficult to quantify., ${ }^{1,2}$ A large United Kingdom (UK) series ${ }^{4}$ established a correlation coefficient of 0.63 . It is therefore difficult to set targets with such a varied range of published data, but a minimum of 0.6 with a desirable target of 0.75 would seem achievable.

One year (2007) of new invasive breast cancer cases at Glasgow Southern General Hospital were identified from histology records and histological size of the lesion at microscopy documented. We obtained ultrasound measurement at diagnosis from the radiologists' reports. The correlation coefficient was assessed using Microsoft Excel ${ }^{\circledR}$ (2003, Microsoft Inc, Redmond, WA) and Statistics with Confidence software. ${ }^{3}$

\section{Results}

Sixty-two new breast cancers were identified at Glasgow Southern General Hospital in 2007. In 16 cases, the diagnosis had been made either by wide-bore needle biopsy only, or with adjuvant therapy administered before excision. Other cases were excluded if there was multifocality, no ultrasound performed, or if they were preinvasive only.

Twenty-seven invasive cancers were eligible and had a histological excision size recorded. These measurements and their comparative ultrasound sizes are shown in Table 1. Pearson's correlation coefficient was calculated at $r=0.73$ by both Microsoft and Statistics with Confidence software packages. The plot graph (Figure 1) shows a somewhat linear relationship and allows for easy identification of outliers.

\section{Discussion}

It is generally understood that ultrasound will tend to underestimate tumor size and will not equal histological measurement; however, there should be a good linear correlation between our measurements and histological size.

Although targets such as being within $1 \mathrm{~cm}$ in a certain percentage of cases have been used in some papers, ${ }^{5}$ we suggest that a meaningful audit is best done by measuring and plotting correlation coefficients. We have used both Microsoft Excel ${ }^{\circledR}$ and software from Altman et al $^{3}$ to calculate correlation coefficient in 27 cases. The latter software allows simultaneous calculation of Pearson's and Spearman's correlation coefficients to be calculated. In our small sample there
Table I Ultrasound and comparative histological size of invasive breast cancer cases at Glasgow Southern General hospital in 2007 $(\mathrm{n}=27)$

\begin{tabular}{|c|c|c|}
\hline Case & Ultrasound size $(\mathrm{mm})$ & Histological size $(\mathrm{mm})$ \\
\hline $\mathrm{I}$ & II & 17 \\
\hline 2 & 14 & 15 \\
\hline 3 & 20 & 40 \\
\hline 4 & 30 & 35 \\
\hline 5 & 23 & 29 \\
\hline 6 & 30 & 20 \\
\hline 7 & II & 13 \\
\hline 8 & 20 & 27 \\
\hline 9 & 7 & 9 \\
\hline 10 & 16 & 22 \\
\hline II & II & 8 \\
\hline 12 & 17 & 18 \\
\hline 13 & 13 & 25 \\
\hline 14 & 17 & 15 \\
\hline 15 & 17 & 15 \\
\hline 16 & 25 & 30 \\
\hline 17 & 24 & 20 \\
\hline 18 & 22 & 23 \\
\hline 19 & 23 & 22 \\
\hline 20 & 8 & 10 \\
\hline 21 & 28 & 36 \\
\hline 22 & II & 15 \\
\hline 23 & 25 & 22 \\
\hline 24 & 18 & 20 \\
\hline 25 & II & 15 \\
\hline 26 & 15 & 20 \\
\hline 27 & 15 & 15 \\
\hline
\end{tabular}

was no significant difference found; the Pearson correlation was 0.73 (95\% confidence interval [CI]: 0.476-0.866) and the Spearman correlation was 0.77 (95\% CI: 0.549-0.889).

While Pearson's correlation coefficient is a good statistical indicator of the linear correlation of measurements, widely differing plots graphs can arise from the same numerical figure. As seen in an example from Anscombe, ${ }^{6}$ all 4 plot diagrams can lead to the same figure for $r$ of 0.816 (Figure 2). For this reason, and to identify outliers, the plot graph is a valuable addition to $r$ value alone.

Individuals can calculate and plot correlation by using readily available software, with very little technical skill required. We have used both Microsoft Excel ${ }^{\circledR}$ and Statistics with Confidence software, ${ }^{3}$ but other programs, including free web-based software, are available. The Statistics with Confidence package allows easy calculation of $\mathrm{CI}^{5}$ for the Pearson's coefficient and gives a good indication of the statistical 


\section{Cancer size correlation}

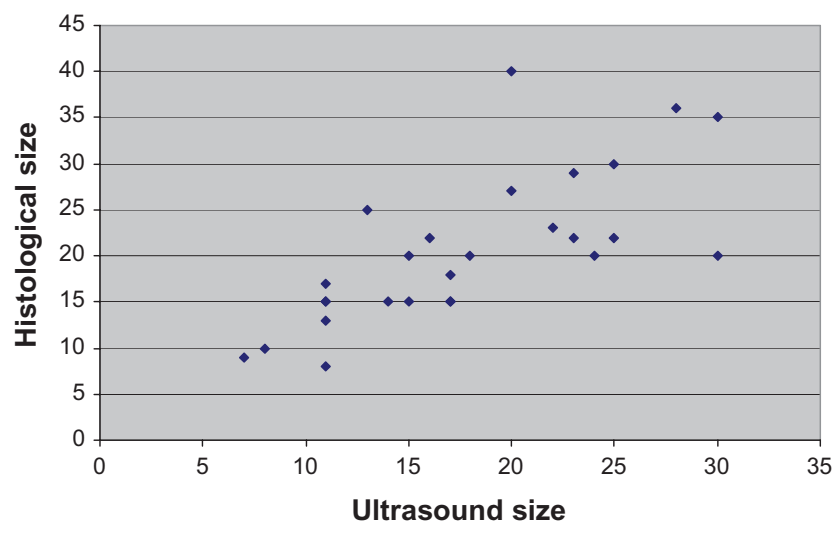

Figure I Plot of histological size compared to ultrasound measurement.
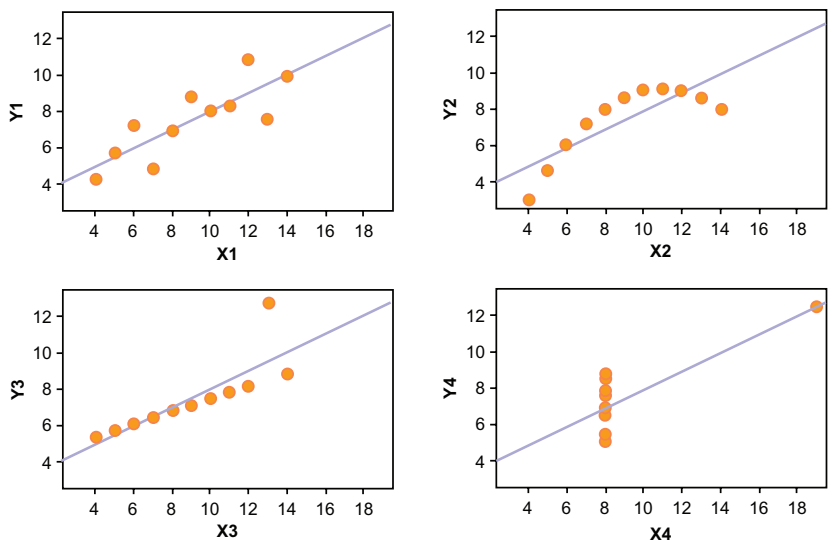

Figure 2 Correlation plot diagrams from Anscombe. ${ }^{6}$ Copyright $(C)$ 1973, American Statistical Association. All rights reserved. Reprinted with permission from Anscombe FJ. Graphs in statistical analysis. Am Staf. 1973;27:17-21.

Note: All four plots have an $r$ value of 0.816 for correlation. significance of the calculated figure. For our small sample, the $95 \%$ CI was $0.48-0.73$. A reasonable sample size is needed since many cancers need to be excluded (ie, multicentric lesions, neoadjuvant treatment cases etc). In this report, the CI of our result was broad. It is partly because of this that we consider the plot diagram to be of value as it can portray the linearity of a relationship and identify outlying measurements for review, rather than just viewing a numerical figure for correlation coefficient alone.

We suggest the following targets based on published reviews: a minimum correlation coefficient 0.6 and an achievable goal of 0.75 . We advocate the use of this measure as a routine audit tool.

\section{Disclosure}

The authors report no conflicts of interest in this work.

\section{References}

1. Allan SA, Cunliffe WJ, Gray J, et al. Pre-operative estimation of primary breast cancer size: a comparison of clinical assessment, mammography and ultrasound. Breast. 2001;10(4):299-305.

2. Pritt B, Ashikaga T, Oppenheimer RG, Weaver DL. Influence of breast cancer histology on the relationship between ultrasound and pathology tumor measurements Mod Pathol. 2004;17:905-910.

3. Altman DG, Machin D, Bryant TN, Gardner MJ. Statistics with Confidence 2nd ed. London: BMJ Books; 2000.

4. Pagllari CM, Wilkinson LS, Given-Wilson RM, Thomas VA, Polonieck J. Correlation of preoperative size of breast carcinoma determined by mammography and ultrasound with final histopathology. RCR Breast Group meeting 2006. http://www.rcrbreastgroup.com/ASM/Edin06/ files/PosterPDFs/P14.pdf

5. Finlayson CA, MacDermott TA. Ultrasound can estimate the pathologic size of infiltrating ductal carcinoma. Arch Surg. 2001;135:158-159.

6. Anscombe FJ. Graphs in statistical analysis. Am Stat. 1973;27:17-21.
Clinical Audit

\section{Publish your work in this journal}

Clinical Audit is an international, peer-reviewed, open access journal focusing on the processes and outcomes of clinical audit in any area of healthcare. All aspects of patient care are addressed within the journal and practitioners from all disciplines are invited to submit their work. Areas covered include: Publication of audits; How an audit has changed practice;

\section{Dovepress}

Practical tips on how to do audits and to avoid pitfalls; How audits have changed patient care; Calls and justifications for new audits. The manuscript management system is completely online and includes a very quick and fair peer-review system, which is all easy to use. Visit http://www.dovepress. com/testimonials.php to read real quotes from published authors. 